\title{
The Usefulness of the Source Images of Magnetic Resonance Angiogram in the Carotid Cavernous Fistula
}

\author{
Bon D. Ku, ${ }^{1}$ Hak Yiung Rhee, ${ }^{2}$ and Sung Sang Yoon ${ }^{3}$ \\ ${ }^{1}$ Department of Neurology, Myongji Hospital, 697-24 HwajungDong DukyangGu \\ Goyang GyeongGi 412-270, Republic of Korea \\ ${ }^{2}$ Department of Neurology, Kyung Hee University Hospital at Ganggong, \\ Seoul, Republic of Korea \\ ${ }^{3}$ Department of Neurology, Kyung Hee University Hospital, Seoul, Republic of Korea
}

Received 14 July 2011; Accepted 24 September 2011

Academic Editor: Jorge Arruga

KEYWORDS: carotid cavernous fistula, magnetic resonance angiography, source image

The cortical venous drainage from carotid-cavernous fistula (CCF) is associated with increased risk of intraparenchymal hemorrhage and may be the clue for the urgent indication of an endovascular treatment [1]. However it is difficult to infer direction of venous drainage from the clinical signs or symptoms of a patient with CCF. The source images of magnetic resonance angiogram (MRA) may useful to detect the direction and magnitude of the collateral circulations in the patient with carotid-cavernous fistula (CCF) [2]. A 68year-old woman presented with progressive bilateral pulsatile tinnitus, headache and diplopia accompanied by swelling of both eyes, the right eye being more severely affected. She underwent surgical reconstruction of fractured facial bone 6 weeks ago due to car accident. From the 30th days after reconstruction, she suffered persistent progressive pulsatile tinnitus and periorbital pain. The MRA revealed marked leakage signals of arterial blood around cavernous sinus (Figure 1). The source image of MRA revealed increased transsellar collaterals, enlarged both sphenoparietal sinus and right side predominant elongated bilateral tortuous superior ophthalmic veins (Figure 2).

\section{FINANCIAL SUPPORT}

This study was supported by a Grant of the Korea Health 21 R\&D Project, Ministry of Health \& Welfare, Republic of Korea (A102065). 


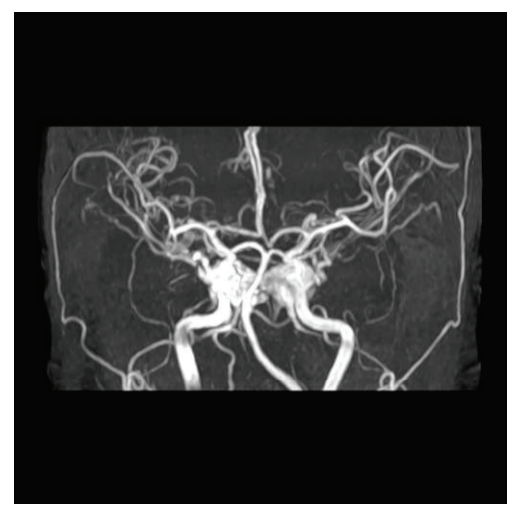

(a)

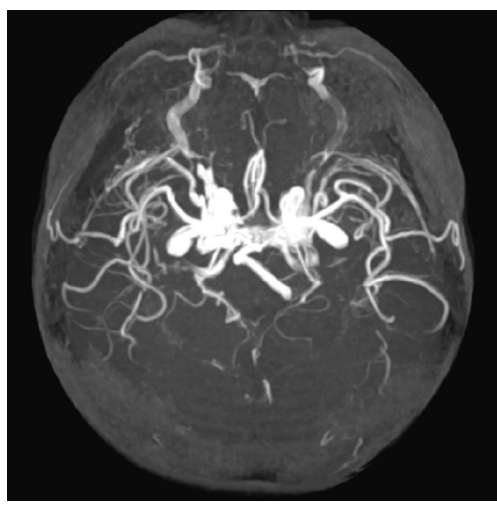

(b)

FIGURE 1: The magnetic resonance angiogram (MRA) of the patient showed increased flow related signals around both cavernous sinuses.

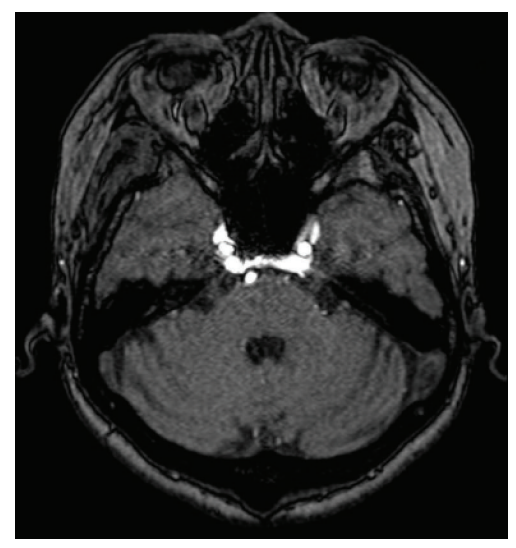

(a)

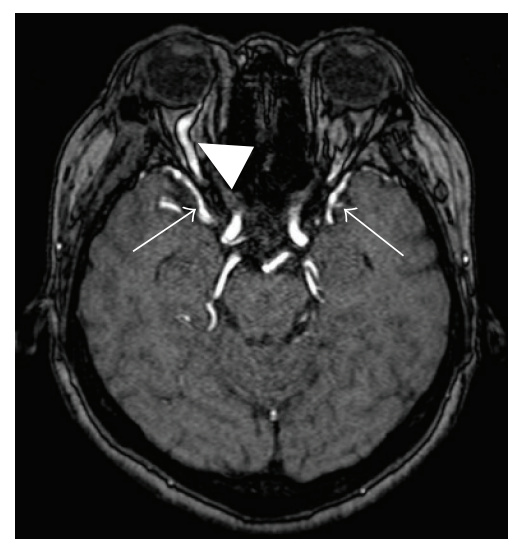

(c)

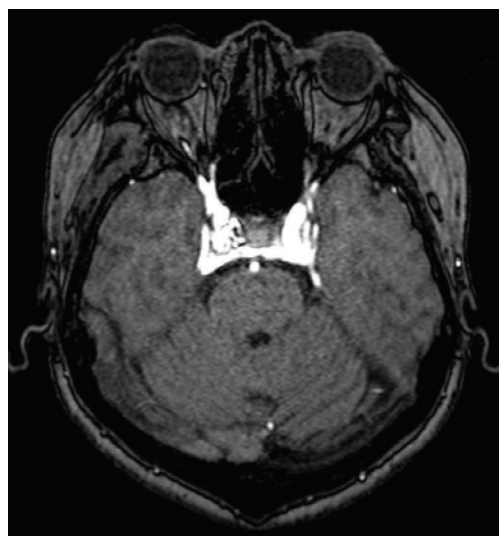

(b)

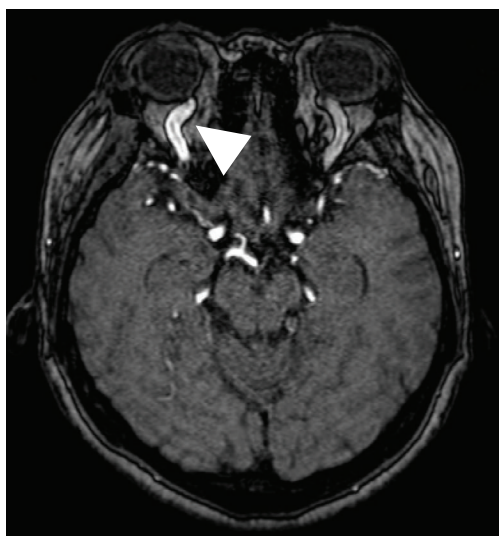

(d)

FIGURE 2: The source image of magnetic resonance angiogram (MRA) revealed increased transsellar collaterals $(\mathrm{a}, \mathrm{b})$, enlarged both inferior cerebral veins $(\mathrm{C}$; arrow) and right side predominant elongated bilateral tortuous superior ophthalmic veins (c, d; arrow head). 


\section{REFERENCES}

[1] V. V. Halbach, G. B. Hieshima, R. T. Higashida, and M. Reicher, "Carotid cavernous fistulae: indications for urgent treatment," American Journal of Roentgenology, vol. 149, no. 3, pp. 587-593, 1987.

[2] Y. F. Tsai, L. K. Chen, C. T. Su, T. N. Lu, C. C. Wu, and C. J. Kuo, "Utility of source images of three-dimensional time-of-flight magnetic resonance angiography in the diagnosis of indirect carotid-cavernous sinus fistulas," Journal of Neuro-Ophthalmology, vol. 24, no. 4, pp. 285-289, 2004.

\section{This article should be cited as follows:}

Bon D. Ku, Hak Yiung Rhee, and Sung Sang Yoon, "The Usefulness of the Source Images of Magnetic Resonance Angiogram in the Carotid Cavernous Fistula," TheScientificWorldJOURNAL, vol. 11, pp. 25792581, 2011. 


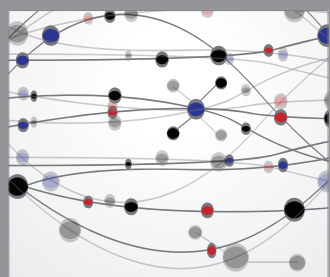

The Scientific World Journal
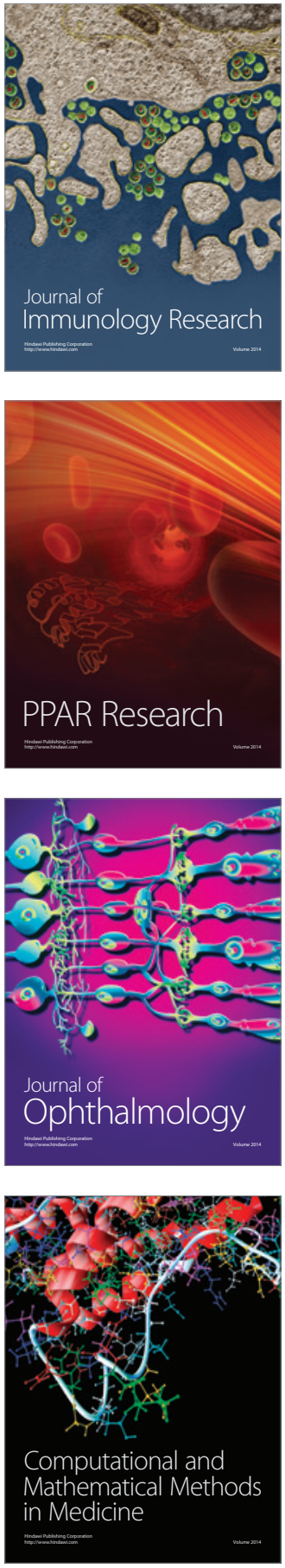

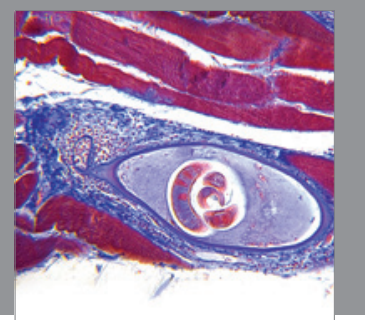

Gastroenterology

Research and Practice
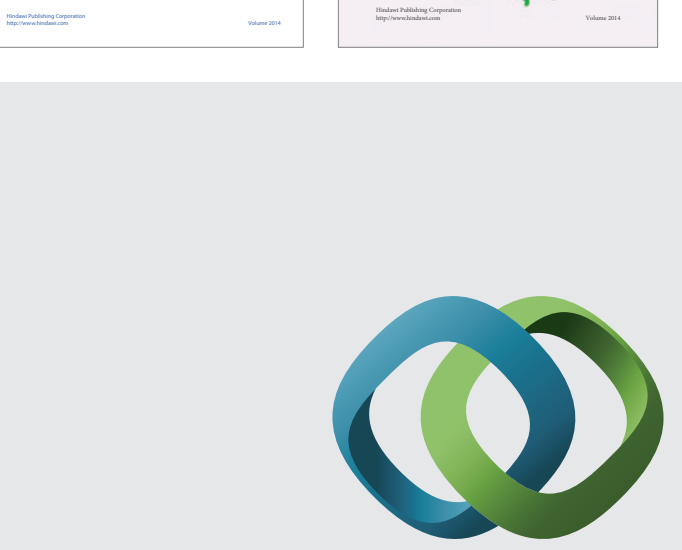

\section{Hindawi}

Submit your manuscripts at

http://www.hindawi.com
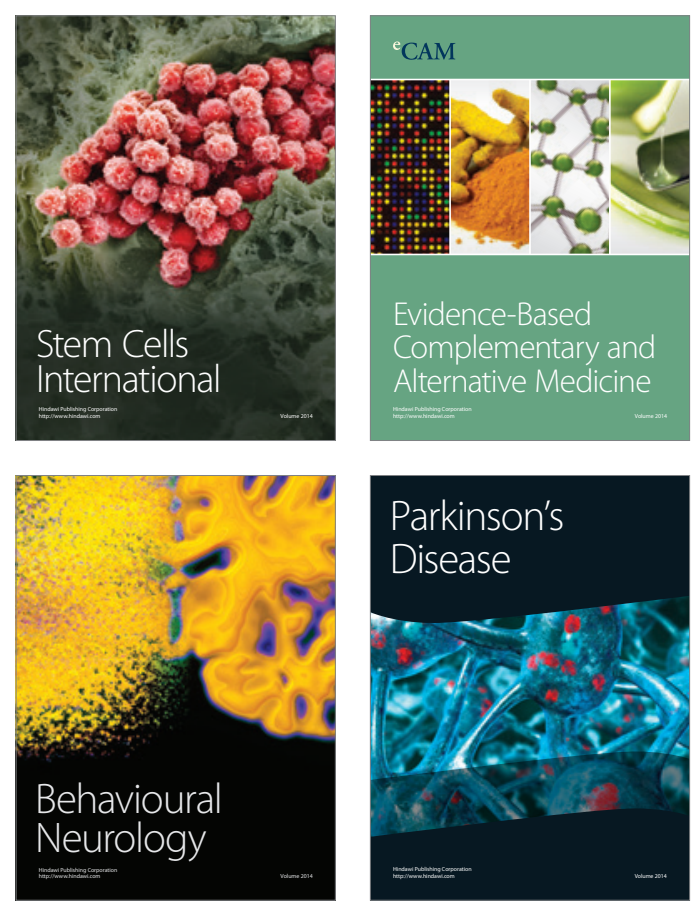

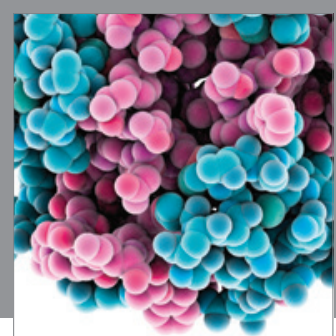

Journal of
Diabetes Research

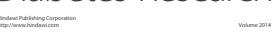

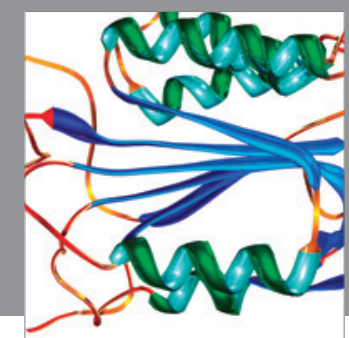

Disease Markers
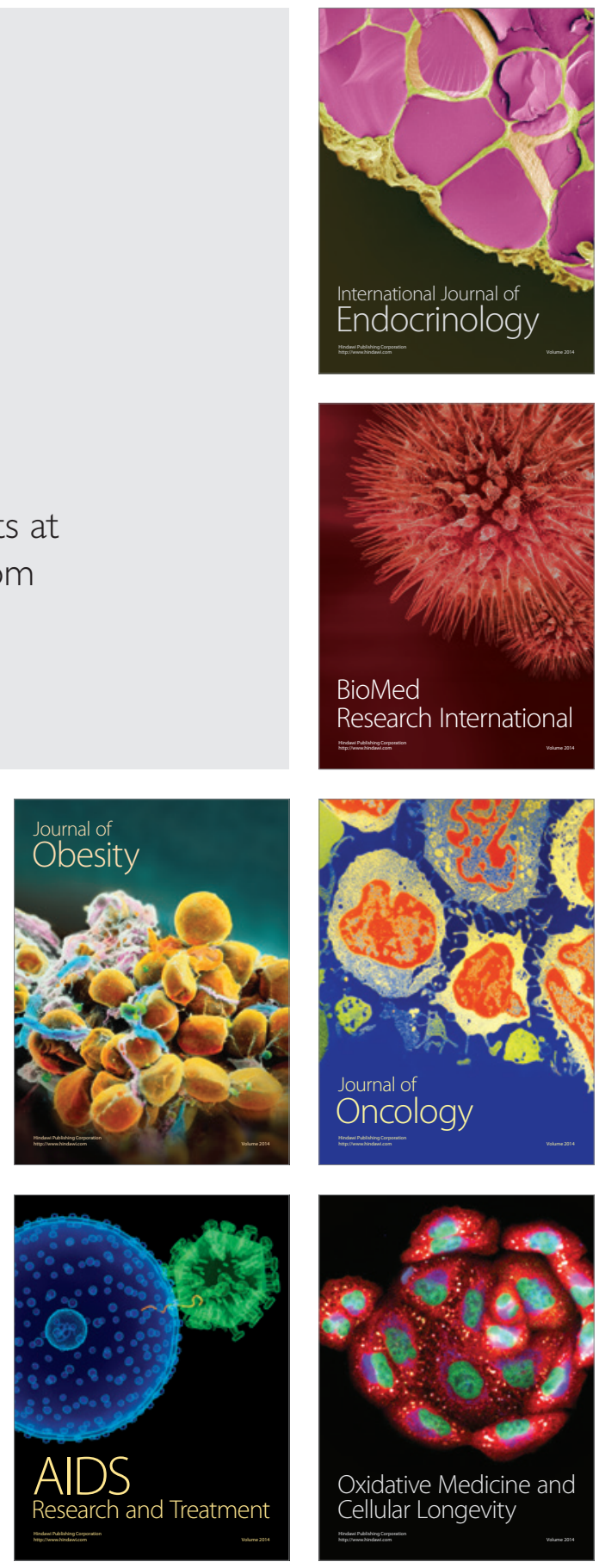